\title{
ÉTICA E MORAL NA ESCOLA: O QUE OS DOCUMENTOS REGULARES DIZEM A RESPEITO?
}

\author{
PROFA. ME. KARINA LUCIANE SILVA DEOLINDO* \\ PROFA. DRA. LUCIANA MARIA CAETANO** \\ PROFA. DRA. BETÂNIA ALVES VEIGA***
}

\begin{abstract}
RESUMO
Objetiva-se identificar quais são os documentos legais que orientam ética e moralmente as práticas pedagógicas dos educadores escolares e quais seriam essas orientações dentro da concepção de educação vigente em nosso país. Conceitua-se o que é moral e o que é ética em nossa sociedade, com base na obra de Piaget. Compreendemos que um ambiente moral na escola, pode favorecer o convívio coletivo, pois a moral autônoma pode ser desenvolvida com mais facilidade. Escolhemos os seguintes documentos para estudo: Diretrizes Curriculares do Curso de Pedagogia (2006), dos Parâmetros Curriculares Nacionais (1997), e do Plano Nacional de Educação (2014). Após a análise dos documentos fizemos uma breve discussão a respeito do papel do professor e da educação moral dos alunos. Por fim, pudemos concluir com base nos documentos estudados e no referencial teórico escolhido, que quando o ambiente educacional e profissional se organiza a partir da adoção da ética e da moral nos processos pedagógicos, os resultados tendem a ser positivos, pois, além de valorizar e desenvolver a competência do professor, a ênfase se faz sobre relações cooperativas, que podem promover o desenvolvimento moral autônomo do aluno.

Palavras-chave: Educação moral e ética. Formação de professores. Documentos educacionais.
\end{abstract}

\footnotetext{
* Mestre e aluna do Grupo de Estudos e Pesquisa do IPUSP.

** Professora titular do Instituto de Psicologia da USP - coordenadora do Grupo de Estudos e Pesquisa no mesmo Instituto.

*** Professora no Centro Universitário das Faculdades Associadas de Ensino - Fae.
} 


\begin{abstract}
The objective is to identify which are the legal documents that ethically and morally guide the pedagogical practices of school educators and which would be these guidelines within the conception of education in force in our country. Conceptualizes what is moral and what is ethical in our society, based on the work of Piaget. We understand that a moral environment at school can favor collective living, as autonomous morality can be developed more easily. We chose the following documents for study: Curricular Guidelines for the Pedagogy Course (2006), the National Curriculum Parameters (1997), and the National Education Plan (2014). After analyzing the documents, we made a brief discussion about the role of the teacher and the moral education of the students. Finally, we were able to conclude based on the studied documents and on the chosen theoretical framework, that when the educational and professional environment is organized based on the adoption of ethics and morals in the pedagogical processes, the results tend to be positive, because in addition to valuing and develop teacher competence, the emphasis is on cooperative relationships, which can promote the student's autonomous moral development.
\end{abstract}

Key-words: Moral and ethical education, Teacher training, Educational documents.

\title{
1. INTRODUÇÃO
}

La Taille (2009) afirma que a moral é objeto de conhecimento e que o sujeito só irá desenvolvê-la se estiver em um ambiente moral. Deste modo, este ambiente pode conter regras, princípios e valores, que são conteúdos morais. As regras são constituídas a partir de formulações do que se pode ou não fazer. Os princípios assim fundamentam as regras, pois se estas dizem o que é permitido ou não ser feito, o princípio diz o porquê é ou não permitido tal ação.Já os valores são investimentos afetivos. O valor é assim atribuído a todo objeto, pessoas, 
ideias, dentre outras coisas que geram sentimento de afeição, e não deixa a pessoa insensível à situação. La Taille (2009, p. 225) explica que: "tomar consciência dos nossos valores, refletir sobre eles e, se necessário, modificá-los, eis um dos papéis da razão como instância reguladora de nossos juízos morais".

O desenvolvimento do juízo moral estudado por Piaget (1932/1994) se caracteriza pelo desenvolvimento da moralidade na criança, pelo seu processo de construção de conhecimentos sobre as regras que regulam sua vida. Segundo La Taille (2009, p. 227), referindo-se aos estudos piagetianos:

À medida que o desenvolvimento do juízo moral ocorre, a moral se torna objeto de conhecimento cada vez mais elaborado e refletido, os princípios ganham paulatinamente primazia em relação às regras, os equacionamentos e a sensibilidade morais se sofisticam, e a liberdade de pensar e de agir se amplia, pois o indivíduo conquista passo a passo sua autonomia.

La Taille (2009, p. 228), com base nos estudos de Piaget, afirma que: "aceita-se que o juízo moral de cada pessoa depende das interações sociais pelas quais passou durante sua vida. Ora, aceitar a importância de tais influências já equivale a julgar que é lícito falar em "educação moral (...)".

A educação moral assim é fundamental para desenvolver o conhecimento normativo. La Taille (2009) acredita ainda que a escola tem um importante papel nessa formação, pois é um espaço público ${ }^{1}$, onde convivem diversas crianças.

As instituições de ensino deste modo também estão imersas em regras e princípios. As crianças podem: pensar, refletir, compreender e participar da organização das regras, para um bom convívio coletivo. É preciso, deste modo, que todas as crianças tenham tratamento igualitário, não sendo aceitos privilégios na

\footnotetext{
1 Nos referimentos a público aqui, não no sentido de "escola gratuita", mas de espaço de trocas entre diversos sujeitos de diferentes culturas e famílias, ou seja, a sociedade.
} 
instituição. Partindo dessa concepção, entendemos que a escola é um local propício ao desenvolvimento da moral, pois possui as condições ideais para o exercício da justiça e da igualdade nas relações. (LA TAILLE 2009).

Conforme a Constituição do Brasil, Capítulo III, Artigo 205 (1988),

A educação, direito de todos e dever do Estado e da família, será promovida e incentivada com a colaboração da sociedade, visando ao pleno desenvolvimento da pessoa, seu preparo para o exercício da cidadania e sua qualificação para o trabalho.

Podemos entender assim que a educação não deve apenas ser direcionada à busca por um bom emprego. Segundo La Taille (2009), a Constituição do Brasil direciona a Educação para a formação de cidadão. Deste modo, com base no autor, entendemos como cidadão um sujeito crítico e moralmente competente, que assume responsabilidades frente ao seu Estado e sociedade.

A discussão da educação moral leva também a se pensar a especificidade dessa educação. Ela pode ser ensinada como um conteúdo e identificada como uma disciplina dentro da escola? La Taille (2009, p. 273), em seu livro "Formação Ética: do tédio ao respeito de si", discute amplamente essa questão e começa falando sobre a moralidade e o ensino religioso. O autor entende que - "tal educação não precisa nem deve ser assimilada ao ensino religioso" posto que, existe moral sem religião, ou seja, o juízo moral não está associado a mandamentos divinos.

Na perspectiva de La Taille (2009, p. 274), “(...) a não ser que se julgue a escola totalmente inócua em termos de influência sobre os valores de seus alunos, não se vê por que não seria útil ela propor formas alternativas de se pensar e experimentar o convívio social". As trocas, que são fundamentais para a aprendizagem da criança, são fruto de conhecimento e de descentração. Nos apoiamos nesse ponto de vista para enfatizar a importância de o professor ter conhecimento do desenvolvimento moral da criança. 
Esta linha de raciocínio resgata Caetano (2012, p. 20) que questiona:

E os professores, o que sabem sobre as relações de respeito com os alunos? Nossa experiência com cursos de formação de professores nos mostra que os professores desconhecem essa teoria, pois as questões de ética e da educação moral na educação raramente são trabalhadas na formação básica do professor, bem como raros também são os cursos de formação continuada sobre o tema. Logo, é preciso que o professor conheça a possibilidade de auxiliar o seu aluno a evoluir nas relações interpessoais, podendo superar o respeito unilateral.

Por fim, podemos concluir que a moral é objeto de conhecimento social, portanto depende do outro, das relações que a criança possui com seus iguais e com os adultos (PIAGET, 1932/1994). Promover relações de cooperação e de respeito mútuo, favorecendo as trocas e os trabalhos em grupo é atitude fundamental para o desenvolvimento da moral autônoma (PIAGET, 1948/1998) Deste modo, compreendemos que um espaço moral, favorece o convívio coletivo, pois a moral autônoma pode ser desenvolvida com mais facilidade em ambiente livre de coações, que valorize o convívio escolar e as virtudes (LA TAILLE, 2009; CAETANO \& DELL'AGLI, 2017).

Assim sendo, acreditamos que os professores e os educadores escolares de um modo geral precisam pensar em uma educação com base ética, e que a partir dos valores universais constituídos, possam orientar a moral dos alunos, buscando assim construir uma sociedade justa e igualitária para todos, que enfatize o bem-estar de todos. Mas para que isso se concretize precisamos de documentos legais que enfatizem e valorizem a ética e moral como componentes essenciais de ensino.

Nesse ponto de análise buscamos responder as seguintes questões: quais são os documentos legais que norteiam os processos pedagógicos dos educadores para desenvolver a autonomia moral de seus alunos? Quais poderiam ser os impactos gerados no ambiente educacional e profissional a partir da adoção da ética e da moral nos processos pedagógicos? 
Oportuno destacar que este artigo tem por objetivo identificar quais são os documentos legais que orientam ética e moralmente as práticas pedagógicas dos educadores escolares e quais seriam essas orientações dentro da concepção de educação vigente em nosso país.

À vista disso, apresentaremos o referencial teórico que evidencia a importância de um ambiente moral que desenvolva plenamente o aluno, assim como reafirma a necessidade de uma formação de qualidade dos professores, com vistas a que estes tenham formação científica para transmitirem valores embasados nos direitos humanos e sociais.

\section{DOCUMENTOS LEGAIS E SUAS ORIENTAÇÕES ACERCA DA ÉTICA E DA MORAL}

Para iniciar a discussão a respeito da importância da formação e competência do professor, realizamos uma análise das Diretrizes Curriculares do Curso de Pedagogia (2006), dos Parâmetros Curriculares Nacionais (1997) e do Plano Nacional de Educação (2014) com o intuito de identificar nestes documentos, diretrizes que fundamentassem a importância do tema moral, para serem trabalhos nas - salas de aula das escolas. A seguir apresentaremos as diretrizes desses documentos que apontam a necessidade da temática na educação dos alunos.

O primeiro documento estudado foi as Diretrizes Curriculares Nacionais para o Curso de Graduação em Pedagogia (2006). Este documento sofreu correções com os Pareceres CNE/CP nos anos de 2005 e 2006. No Art. $2^{\circ}$ dos Pareceres CNE/CP 5/2005 e 3/2006, podemos visualizar as disposições para o Curso de Pedagogia, que garantem o exercício da docência na Educação Infantil e nos anos iniciais do Ensino Fundamental, bem como no Ensino Médio, como em cursos de Educação Profissional.

Podemos também visualizar uma preocupação do Curso de Pedagogia com a formação dos graduandos, em que os Pareceres CNE/CP 5/2005 e 3/2006 elencam muitas metas de qualidade 
para a formação dos discentes, evidenciando entre elas a formação ética de seus alunos. Apresentaremos a seguir os artigos e parágrafos que afirmam tal posição nas Diretrizes Curriculares Nacionais para o Curso de Graduação em Pedagogia (2006).

$\int 1^{\circ}$ Compreende-se a docência como ação educativa e processo pedagógico metódico e intencional, construído em relações sociais, étnico-raciais e produtivas, as quais influenciam conceitos, princípios e objetivos da Pedagogia, desenvolvendo-se na articulação entre conhecimentos científicos e culturais, valores éticos e estéticos inerentes a processos de aprendizagem, de socialização e de construção do conhecimento, no âmbito do diálogo entre diferentes visões de mundo.

Art. $3^{\circ} \mathrm{O}$ estudante de Pedagogia trabalhará com um repertório de informações e habilidades composto por pluralidade de conhecimentos teóricos e práticos, cuja consolidação será proporcionada no exercício da profissão, fundamentando-se em princípios de interdisciplinaridade, contextualização, democratização, pertinência e relevância social, ética e sensibilidade afetiva e estética.

Art. $5^{\circ} \mathrm{O}$ egresso do curso de Pedagogia deverá estar apto a:

I - atuar com ética e compromisso com vistas à construção de uma sociedade justa, equânime, igualitária;

Art. $6^{\circ}$ A estrutura do curso de Pedagogia, respeitadas a diversidade nacional e a autonomia pedagógica das instituições, constituir-se-á de:

e) aplicação, em práticas educativas, de conhecimentos de processos de desenvolvimento de crianças, adolescentes, jovens e adultos, nas dimensões física, cognitiva, afetiva, estética, cultural, lúdica, artística, ética e biossocial;

k) atenção às questões atinentes à ética, à estética e à ludicidade, no contexto do exercício profissional, em âmbitos escolares e não-escolares, articulando o saber acadêmico, a pesquisa, a extensão e a prática educativa.

O documento ressalta em diversos parágrafos a importância da ética para um trabalho de qualidade, que eleve a qualidade da educação dos discentes do curso, assim como sua atuação profissional. Deste modo, fica assegurada a autonomia intelectual 
e a sólida formação dos discentes em Pedagogia, já que o futuro profissional terá condições, caso tenha interesse e mediante estudos complementares, de se dedicar a algum outro campo de atuação profissional atualmente previsto para o Pedagogo.

Outro documento muito importante para a educação é: "Os Parâmetros Curriculares Nacionais (PCN)" (1997), que tem por objetivo auxiliar os professores na execução de seu trabalho. De acordo com Mesti (2004, p.9), “[o] propósito declarado do Ministério da Educação é apontar metas de qualidade que ajudem o aluno a enfrentar o mundo atual como cidadão participativo, reflexivo e autônomo, conhecedor de seus direitos e deveres". Podemos entender assim, que o objetivo do documento é fundamentar uma educação de qualidade, que não fique restrita apenas ao cognitivo, mas que vise outros aspectos do desenvolvimento do aluno.

Em sua introdução, o documento (PCN/Ética, 1997) afirma sua preocupação com uma formação de qualidade, comprometida com a cidadania. Esclarece que sua composição é embasada nos seguintes direitos: dignidade da pessoa humana; igualdade de direitos; participação; e corresponsabilidade pela vida social, e justifica seu posicionamento enfatizando que: "Trata-se de um fazer conjunto, um fazer-se na cumplicidade entre aprender e ensinar, orientado por um desejo de superação e transformação" (BRASIL, 1997, p.24). Dessa forma, entendemos que o documento busca a união entre o professor e o aluno, a escola e a comunidade, pois tanto se ensina, como se aprende nesse processo de aquisição de conhecimento na escola.

Os objetivos descritos no PCN/Ética (1997) indicam o que um aluno do ensino fundamental pode ser capaz de fazer, entre os quais destacamos:

- compreender a cidadania como participação social e política, assim como exercício de direitos e deveres políticos, civis e sociais, adotando, no dia-a-dia, atitudes de solidariedade, cooperação e repúdio às injustiças, respeitando o outro e exigindo para si o mesmo respeito; 
- desenvolver o conhecimento ajustado de si mesmo e o sentimento desconfiança em suas capacidades afetiva, física, cognitiva, ética, estética, de inter-relação pessoal e de inserção social, para agir com perseverança na busca de conhecimento e no exercício da cidadania (BRASIL, 1997, p.9).

Dessa forma, podemos compreender em ambos os objetivos que constituem o PCN/Ética (1997), a valorização do desenvolvimento do aluno integralmente, na medida em que evidenciam tanto o desenvolvimento intelectual, como o afetivo e moral. A proposta é de formar o aluno para a cidadania, favorecendo a criticidade e autonomia, ou seja, um aluno que compreenda sua participação social e política, assim como seus direitos e deveres civis e sociais, e que principalmente se posicione de maneira responsável e construtiva em diferentes situações (MESTI, 2004).

Como o tema ética é apresentado no PCN/Ética (1997) como sendo um assunto transversal, nos utilizaremos de La Taille (2009) para explicar a transversalidade, visto que ele é um dos colaboradores na elaboração do documento, bem como pesquisador reconhecido na área da psicologia moral. O autor afirma que a transversalidade já era citada na área da educação há muito tempo, mas não com essa nomenclatura.

O próprio Piaget chama atenção para o fato de a moral não deve ser uma disciplina específica, e pode estar presente no ensino de um modo geral (PIAGET, 1948/1988). A transversalidade foi fundamentada no Brasil em 1997, nos Parâmetros Curriculares Nacionais para o Ensino Fundamental. Os temas transversais são: meio ambiente, pluralidade cultural, saúde, consumo, trabalho, orientação sexual e ética.

A transversalidade é composta pela perspectiva de não fragmentação do ensino, ou seja, os conteúdos apresentados como temas transversais não seriam constituídos por disciplinas à parte, mas constituem um conteúdo dentro das próprias disciplinas escolares. Contempla-se então a união dos conteúdos e não mais sua fragmentação. Espera-se também o trabalho cole- 
tivo entre os professores de modo que estes possam discutir os temas, e que juntos possam buscar formas para que eles sejam trabalhados em sala de aula.

Os critérios adotados pelo documento, para constituição dos temas transversais avaliam a situação atual da sociedade. O documento assim elegeu questões sociais que poderiam ser trabalhadas dentro das escolas, pelos temas transversais, para promover a cidadania e a democracia dentro das mesmas. Os critérios utilizados foram: Urgência Social; Abrangência Nacional; Possibilidade de ensino e aprendizagem no ensino fundamental; Favorecer a compreensão da realidade e a participação social (PCN/Ética ,1997). De acordo com o documento, tais critérios foram auxiliadores na construção e promoção dos temas dentro das escolas, pois abrangem temas fundamentais para as mesmas.

Para tanto, os Parâmetros Curriculares Nacionais (PCN/Ética) de 1997, apresentam o tema transversal ética da seguinte forma:

A Ética diz respeito às reflexões sobre as condutas humanas. (...) A questão central das preocupações éticas é a da justiça entendida como inspirada pelos valores de igualdade e equidade. $\mathrm{Na}$ escola, o tema Ética encontrasse, em primeiro lugar, nas próprias relações entre os agentes que constituem essa instituição: alunos, professores, funcionários e pais. (...) Em suma, a reflexão sobre as diversas faces das condutas humanas deve fazer parte dos objetivos maiores da escola comprometida com a formação para a cidadania. Partindo dessa perspectiva, o tema Ética traz a proposta de que a escola realize um trabalho que possibilite o desenvolvimento da autonomia moral, condição para a reflexão ética (...) (1997 p. 26).

Portanto podemos compreender que o desenvolvimento da moralidade para a autonomia é condição necessária para a formação da cidadania do sujeito. As relações dentro do ambiente escolar são morais e precisam ser devidamente compreendidas e desenvolvidas em função do respeito, da justiça e da autonomia do sujeito (DEOLINDO, CAETANO \& YAEGASHI, 2018). Entendemos que as escolas são fonte de conhecimento tanto intelectual, quanto moral, por isso é preciso que esse conteúdo transversal seja trabalhado nas instituições educacionais 
Com relação à aprendizagem de valores e atitudes, o documento afirma que:

Normas e regras, por sua vez, são aqui entendidas como dispositivos que orientam padrões de conduta a serem definidos e compartilhados pelos membros de um grupo. Os valores orientam as ações e possibilitam fazer juízo crítico sobre o que se toma como objeto de análise. (BRASIL, 1997, p. 33).

Esse entendimento ressalta a necessidade de tanto as normas como os valores serem trabalhados dentro das escolas e aponta que o conteúdo, assim como as relações e ações que os professores possuem com seus alunos, interferem na aprendizagem e desenvolvimento do discente. Por isso a importância de levar em conta os conhecimentos (e sentimentos) prévios dos alunos em relação aos conteúdos eleitos para o ensino. "Apesar de ser um trabalho complexo, é necessário acompanhar de forma cuidadosa o processo dos alunos para compreender seus comportamentos no contexto amplo do desenvolvimento moral e social" (BRASIL, 1997, p.34).

Entendemos assim com base no PCN/Ética (1997) que o desenvolvimento de atitudes implica conhecer diferentes valores, compreendê-los, usá-los, questioná-los criticamente e posteriormente escolhê-los livremente. Dessa forma, esse processo é um procedimento de construção que auxiliará o desenvolvimento da autonomia. E para que essa autonomia se desenvolva, é necessário trocas, cooperação, ou seja, ação coletiva, como também relações de poder não autoritárias.

Mas para que isso ocorra dentro das escolas é necessário que os valores eleitos e a intenção de ensiná-los sejam compreendidos por todos, principalmente pelos alunos, e que o trabalho pedagógico seja fundamentado na possibilidade de discussão e questionamentos. Assim sendo, entende-se que os conflitos são próprios dos processos democráticos, e por isso não podem ser evitados e nem rejeitados (BRASIL, 1997).

De acordo com o documento, a valorização dos questionamentos e das discussões auxiliam as mudanças, que devem 
ocorrer em função da qualidade das situações didáticas, que podem potencializar tal capacidade e possibilitar o aprendizado de modo a utilizá-lo de forma consequente, responsável e eficaz.

O documento faz a seguinte observação, que vai ao encontro da educação moral, proposta por Piaget (1930/1932/1948):

Como exemplos temos experiências educativas de construção coletiva de regras de convívio escolar, de discussão coletiva de situações problema na classe e na escola, de projetos de intervenção no espaço escolar e extraescolar que podem ser adaptadas aos níveis de escolaridade de acordo com a possibilidade dos alunos (BRASIL, 1997, p.35).

Com isso fica evidente a importância das relações de cooperação e de trocas entre iguais em sala de aula. A construção das regras e os trabalhos em grupo fazem com que os pontos de vista sejam revistos e as opiniões mudadas, favorecendo assim o desenvolvimento da moral autônoma. O PCN/Ética (1997) ainda ressalta a importância do professor, observando que a atuação dele, é fundamental para o desenvolvimento e aprendizagem do aluno. "Estabelecer relações de autonomia, necessárias à postura crítica, participativa e livre pressupõe um longo processo de aprendizagem até que os alunos sejam capazes de atuar segundo seus próprios juízos" (BRASIL, 1997, p.35).

Somente quando compreendemos a necessidade da relação entre a educação e a ética é que entendemos porque a ética possui destaque nas diretrizes do Plano Nacional de Educação no Brasil. A lei no 13.005, de junho de 2014, faz referência à aprovação do Plano Nacional de Educação (PNE 2014-2024).

Podemos verificar que no Plano Nacional de Educação (PNE) diversos enunciados remetem à ética e/ou moral de forma específica ou de forma geral:

(I) superação das desigualdades educacionais, com ênfase na promoção da cidadania e na erradicação de todas as formas de discriminação;

(II) formação para o trabalho e para a cidadania, com ênfase nos valores morais e éticos em que se fundamenta a sociedade; 
(III) promoção do princípio da gestão democrática da educação pública;

(IV) promoção humanística, científica, cultural e tecnológica do País;

(V) promoção dos princípios do respeito aos direitos humanos, à diversidade e à sustentabilidade socioambiental. (BRASIL, 2014).

De acordo com Menezes e Garces (2015), o PNE evidencia a importância da ética quando especificamente a relaciona aos processos de formação do ser humano, ou seja, entende-se que a formação educacional cidadã seja permeada pela formação ética. Desta forma, conclui-se que as referências a valores morais e éticos que aparecem nas diretrizes dizem respeito a valores que permeiam a vida do indivíduo em sua individualidade e coletividade.

As diretrizes apresentadas pelo PNE (2014) acerca da ética e da moral reforçam principalmente o aspecto da formação cidadã por meio da promoção de valores que precisam se efetivar para além da normatividade, não por imposição, mas porque são reconhecidos em sua natureza como reais e porque traduzem as expectativas da vida de todos para todos (MENEZES E GARCES, 2015).

Segundo Severino (2006, p. 621),

A educação não é apenas um processo institucional e instrucional, que é o seu lado visível, mas é fundamentalmente um investimento formativo do humano, seja na particularidade da relação pedagógica pessoal, seja no âmbito da relação social coletiva. Por isso, a interação docente é considerada mediação universal e insubstituível dessa formação, tendo-se em vista a condição de educabilidade do homem. Por isso a educação deve ser sempre entendida como um investimento feito pelos sujeitos dos recursos exteriores visando o desenvolvimento de sua subjetividade. Nesse sentido educar-se é apreender-se cada vez mais como sujeitos.

Desta forma, entendemos que a moral e a ética devem compreender o respeito, o cultivo e a valorização da democracia efetiva, a preservação da vida e do ser humano em todas as esferas de suas relações, a promoção à participação ativa na construção dos direitos, bem como na definição acerca do bem comum. 
Ahlert (2003, p. 163) afirma que

"todo processo de construção de conhecimento, de ensino-aprendizagem, de educação formal e informal, de educação técnica e científica, precisa ter incorporado urgentemente o imperativo ético para promover a inclusão de todos e de tudo”.

Deste modo, compreendemos que a ética assume caráter inclusivo, pois se relaciona diretamente com o coletivo.

Mas para que isso se efetive realmente, ou seja, para que a relação entre educação e ética se concretize em nossa sociedade será necessário então reconhecer que esta proposta deve significar em nosso tempo um momento de ruptura com processos de dominação excludentes e sem dignidade. E que com dessa ruptura nasçam também propostas mais inclusivas e dignas, as quais não podem se constituir sem a participação de todos.

Concluímos assim com base nos documentos estudados, que estes e a comunidade educacional que os compôs compreendem a importância de uma formação de qualidade, que esta não se fundamenta apenas no desenvolvimento cognitivo, mas que abarca outros vários aspectos que estão ligados ao desenvolvimento do educando. E com isso enfatiza a relevância da formação integral, de um sujeito crítico e de um cidadão competente.

Ainda de acordo com La Taille (2009), a Constituição do Brasil direciona a educação para a formação de cidadão: um sujeito crítico e moralmente competente, que assume responsabilidades frente ao seu Estado e sociedade.

Portanto, os documentos discutidos enfatizam a educação ética, pois valorizam as trocas, a cooperação, os trabalhos em grupo, evidenciando que para uma formação de qualidade o aluno necessita construir seu próprio conhecimento. Mas para que o profissional esteja apto a atuar segundo esses documentos organizadores e referenciadores da educação, que tipo de competência precisam construir? Quais conhecimentos precisam ser garantidos em sua formação? 


\section{PAPEL DO PROFESSOR NA EDUCAÇÃO MORAL E ÉTICA}

O sociólogo Perrenoud (2002) enfatiza que é necessário que os países e as instituições escolares tratem a educação como algo democrático, ou então irão deixá-la apoiada na reprodução das desigualdades sociais. Nessa linha de representação as massas são obrigadas a seguir o pensamento das classes dominantes que comandam o país.

Para o autor, o professor precisa educar para a cidadania e para a construção de competências. Perrenoud (2002) elenca sete requisitos para professor, para que ele possa desenvolver a cidadania e a competência em seus alunos poderia ser: confiável; intermediário intercultural; interceder numa comunidade educativa; avalizar a Lei; preparar uma vida democrática; conduzir a cultura e ser um intelectual.

O pesquisador complementa que para que este professor seja construtor de conhecimento e de competências ele pode: ser um organizador de uma pedagogia com base construtivista; que aprove o sentido dos saberes; que crie condições de aprendizagem; que dirija a heterogeneidade; e que adeque os processos e percursos de formação (PERRENOUD, 2002).

Com relação à competência do professor, o que se espera é:

(...) um professor com capacidade crítica e inovadora, capaz de participar nos processos de tomada de decisão, de produção de conhecimento, de participação coletiva, consciente do significado da educação. Enfim, que seja um profissional formado para compreender o contexto social no qual se efetivará sua atividade docente (VEIGA e VIANA, 2010, p. 26).

Deste modo, compreendemos que para que tais requisitos sejam contemplados na formação e atuação dos professores, é necessário que a prática reflexiva e a implicação crítica dos professores sejam atitudes fundamentais em sua formação, assim como para os profissionais atuais.

Para Perrenoud (2002), o professor, além de preparar sua aula e estar em sala de aula, necessita se manter em constante 
formação e aprendizagem. Deve ser crítico e atento às mudanças e transformações sociais e educacionais, lutar por um ensino de qualidade, além de ser sujeito ativo nesse processo.

Macedo (2005) também compreende a importância da reflexão na formação e atuação dos professores. Segundo o autor,

[o] magistério, como muitas profissões, precisa ser trabalhado de uma forma reflexiva no sentido forte dessa palavra. A escola como parte de uma sociedade complexa, a que se quer para todas as crianças deve saber oferecer algo melhor para todas elas, em sua diversidade e singularidade, no que de bom, ruim, torto, insuficiente elas trazem de sua vida lá fora. Praticar a reflexão e refletir sobre a prática é uma das condições para isso (MACEDO, 2005, p. 32).

Dessa forma, refletir, segundo o autor, é repensar a prática, sua atuação profissional, sua concepção de ensino e de ensinar. É colocar em foco suas ideias e acrescentar novas possibilidades e retirar o que não deu certo. É avaliar o seu plano de ação, é olhar com outros olhos, é se deixar questionar e ser questionado, para que assim os erros possam ser corrigidos, as atividades reformuladas e a prática, modificada, sempre que necessário e principalmente, que todas essas estratégias sejam usadas em prol do aluno, para a sua aprendizagem e desenvolvimento. "Hoje, espera-se que o professor ensine segundo a lógica da inclusão, o que implica que ensinar e aprender, na perspectiva desse profissional, sejam considerados indissociáveis" (MACEDO, 2005, p. 32).

A prática reflexiva, deste modo, está estritamente ligada à prática em sala de aula, ao planejamento, ao pensamento e à resolução de conflitos. Entendemos, assim, que a reflexão é a avaliação do que foi feito e do que ainda pode ser feito, é uma tomada de iniciativa para melhorar a atuação como professor, como aluno e como sujeito. E para que isso ocorra é necessário "assumir riscos, tomar decisões, mobilizar recursos, atualizar e rever esquemas, assumir a incompletude ou insuficiência das coisas" (MACEDO, 2005, p. 42-43). 
Perrenoud (2002, p. 15) ainda completa que a formação de professores deve estar pautada em,

(...) uma visão de escola que visa democratizar o acesso aos saberes, a desenvolver a autonomia dos sujeitos, seu senso crítico, suas competências de atores sociais, sua capacidade de construir e defender um determinado ponto de vista. Esses princípios passam pelo reconhecimento da autonomia e da responsabilidade profissionais dos professores, tanto individual quanto coletivamente.

Dessa forma, entendemos que a educação moral é condição principal para o desenvolvimento da moral autônoma. Mas para que ela possa se desenvolver é necessário que os alunos estejam em um ambiente propício para tal desenvolvimento, ou seja, que eles não estejam imersos em um ambiente autoritário e coercitivo. Enfatizamos a importância da cooperação e dos trabalhos em grupo, das trocas e discussões em sala de aula, como ponto fundamental para o desenvolvimento da personalidade moral do sujeito.

\section{CONSIDERAÇÕES FINAIS}

Podemos concluir, deste modo, com base nos documentos apresentados - Diretrizes para o curso de Pedagogia (2006), PCN/ Ética (1997) e o PNE (2014) - que estes orientam os educadores para uma formação para a cidadania, pois priorizam uma formação de qualidade que vai além do desenvolvimento cognitivo e abrange outros muitos aspectos do desenvolvimento da criança.

Os documentos e os estudos apontados também enfatizam a necessidade de investimento na formação contínua do professor, de modo que ele conquiste as três competências descritas anteriormente: capacidade de tomar decisões; capacidade de mobilizar recursos e saber agir, enquanto construção; capacidade de coordenação e articulação de esquemas de ação ou de pensamento. Estas competências são necessárias para atender aos objetivos máximos da educação brasileira: a formação para a autonomia moral e intelectual, pois apenas aquele que sabe pensar 
e agir de forma moral conhece os seus direitos e deveres e tem condições concretas de se posicionar no mundo como cidadão.

Com isso poderíamos dizer que os impactos gerados no ambiente educacional e profissional a partir da adoção da ética e da moral nos processos pedagógicos serão positivos, pois além de valorizarmos e desenvolvermos a competência do professor, estaremos dando ênfase a um ambiente cooperativo que desenvolverá o aluno em direção a uma moral autônoma que é embasada em princípios éticos.

\section{REFERÊNCIAS}

AHLERT, Alvori. A eticidade da educação: o discurso de uma práxis solidária/universal. 2. ed. Ijuí, RS: Unijuí, 2003. (Coleção Fronteiras da Educação).

BRASIL. Constituição (1988). Constituição da República Federativa do Brasil. Brasília, DF: Centro Gráfico, 1988.

Secretaria de Educação Fundamental.Parâmetros curriculares nacionais: apresentação dos temas transversais, ética / Secretaria de Educação Fundamental. - Brasília: MEC/SEF, 1997. 146p.

Conselho Nacional de Educação. Resolução CNE/CP 1/2006. Diário Oficial da União, Brasília, 16 de maio de 2006, Seção 1, p.11.

. Lei n.13.005, de 25 de junho de 2014. Aprova o Plano Nacional de Educação - PNE e dá outras providências. Diário Oficial da União, Brasília, DF., 26 jun 2014. Disponível em: <https://www.planalto.gov.br/ccivil_03/_ ato2011-2014/2014/lei/113005.htm>.

CAETANO, L. M. Concepções educativas de pais e professores sobre respeito: o sentimento de obrigação moral. In: CAETANO, L. M. (Org.) A escola contemporânea e os novos desafios aos educadores. São Paulo: Paulinas, 2012, p. 13-41.

CAETANO, L. M.; DELL' AGLI, Betânia Alves Veiga . Concepções Educativas Morais de Professores. Arquivos Brasileiros de Psicologia (Rio de Janeiro. 1979), v. 3, p. 167-182, 2017.

DEOLINDO, K. L. S.; CAETANO, L. M. ; YAEGASHI, S. F. R. Concepções educativas morais de graduandos de Pedagogia. Revista de Educação (PUCCAMP), v. 23, p. 471, 2018. 
LA TAILLE, Y. Formação Ética: do tédio ao respeito de si. Porto Alegre: Artmed, 2009.

MACEDO, L. Ensaios Pedagógicos: como construir uma escola para todos? Porto Alegre: Artmed, 2005.

MENEZES, Ederson Malheiros; GARCES, Solange Beatriz Billig. ENUNCIADOS SOBRE ÉTICA A PARTIR DAS DIRETRIZES DO PLANO NACIONAL DE EDUCAÇÃO (PNE - 2014-2024). Anais XVII Seminário Internacional de Educação no MERCOSUL, Universidade de Cruz Alta - UNICRUZ, 2015.

MESTI, L. R. Comunicação Institucional do Parâmetro Curricular Ética (MEC, Brasil, 1997). Tese de Doutorado em Comunicação e Semiótica. Pontifícia Universidade Católica de São Paulo, 2004.

PERRENOUD, P. A formação dos Professores no Século XXI. In: PERRENOUD, P. THURKER, M. G. As competências para ensinar no século XXI: A formação dos professores e o desafio da avaliação. Porto Alegre: Artmed, 2002. p.11-59

PIAGET, J. Para onde vai a educação? Tradução de Ivete Braga. 10 ed. Rio de Janeiro: José Olympio, 1948/1988.

O juízo moral na criança. Tradução de Elzon Lenardon. São Paulo: Summus, 1932/1994.

. Os procedimentos da educação moral. In: MACEDO, L. de. Cinco estudos de educação moral. São Paulo: Caso do Psicólogo, 1930/1996. p.1-36.

SEVERINO, A. J. A busca do sentido da formação humana: tarefa da filosofia da educação. Educação e Pesquisa, São Paulo, v. 32, n. 3, p. 619-634, 2006.

VEIGA, I. P. A., VIANA, C. M. Q. Q. Formação de professores: um campo de possibilidades inovadoras. In: VEIGA, I. P. A., SILVA, E. F. da (Orgs.). A escola mudou. Que mude a formação de professores. Campinas, SP: Papirus, 2010, p. 13-34. 